\title{
The Mace-head: A Significant Evidence of the Early Cultural Interaction between West and East
}

\author{
Li Shuicheng \\ Peking University
}

\begin{abstract}
The archaeological evidence available so far has revealed that the earliest mace-heads first appeared in the Near East about 10,000 BP. along with the early development and spread of agriculture. After that maceheads began to spread throughout the ancient world: southward to Ancient Egypt Kingdom in North Africa, and northwest to Europe and then to the Eurasian steppe of central Asia and Siberia. Eventually, this movement gradually arrived at the Northwestern region of China. In China, mace-heads were found only in Xinjiang, Gansu, Qinghai and Western Shaanxi in Northwestern Chine. In fact, the morphology of these objects is quite similar to those found outside China. The author assumes that maces, as they bear special and symbolic functions, are not the original or indigenous cultural trait of Chinese civilization. Instead, they are more likely to be exotic goods coming from out-side. The author argues the reasons can be summarized as follow: first, mace-heads in the Near East significantly predate all counterparts in China. Second, the amounts of mace-heads found in China are relatively limited. Third, mace-head discoveries in China are concentrated only in the northwestern area, a pattern explicitly indicating the Western origin of this type of artifacts.
\end{abstract}

From the very beginning of the modern field of archaeology in China in 1921, the question of the origin of ancient Chinese culture has been a focus of academic discussion. For instance, Dr. J. G. Andersson (Fig. 1) initially considered the Yangshao Culture (4900-3000 BCE) as the earliest stage in the emergence of Chinese civilization (Andersson 1923). Later, under the influence of some western scholars, Anderson accepted the model that found Chinese culture as originating in the West. Subsequently, he focused on the northwestern regions of China in search of evidence related to the earliest stages of Chinese civilization (Andersson 1925).

Social Evolution \& History, Vol. 17 No. 2, September 2018 258-272

(C) 2018 'Uchitel' Publishing House

DOI:10.30884/seh/2018.02.14 


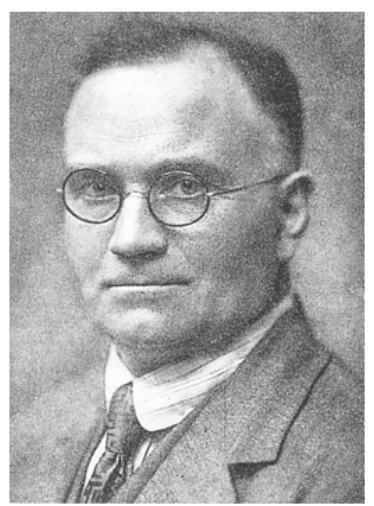

Fig. 1. Dr. J. G. Andersson

Although the 'Western origin theory' of Chinese culture has been challenged and criticized from the beginning, there was not any study for a long time that sufficiently elucidated and pin-pointed the provenance of ancient Chinese culture given the scarcity of evidence. For many Chinese scholars during that time, the "western-origin theory" became a longstanding dilemma.

Since the 1950s, numerous archaeological discoveries have rejected the idea of 'Chinese culture coming from the West' and Chinese scholars gradually have established the theory of 'Chinese culture originating indigenously' - in the main valleys of the Yellow River, also known as the Central Plains. To a certain extent, the dispute has even become a controversial question debated on the philosophical level.

In fact, no regional culture has ever been completely isolated in the history of world. Archaeology has shown, irrefutably, that cultural exchange played a crucial role in the development of all ancient civilization even in their earliest of stages. Nonetheless, the ways in which cultural interaction was present may be varied dramatically: in some cases the interaction involves large-scale replacement, conquest, and subjugation, while in some other cases the interaction involves explicit assimilation. No matter how different these ways would be, cultural interactions always play an essential role in the development and evolution of human society, and ancient China is no exception to this rule.

Since the 1980s, plentiful archaeological discoveries have supplied abundant data for the reconstruction of Chinese prehistory. These new finds have not only moved most Chinese archaeologists to abandon the theory that presumes the development of Chinese civilization was in the Central Plains, but has led to the realization that ancient Chinese culture had emerged through cultural interaction among different regions ( $\mathrm{Su}$ 1997). Cultural interaction had developed gradually from inner to outer China and eventually fostered direct or indirect communication between 
East and West. In the last 20 years or so, a series of new archaeological finds in northwestern China have clarified the pathways, chronologies and scales of early cultural contact that took place along the ancient Silk Road (Li 2002). Among these miscellaneous finds, the mace head provides an important case study in our understanding of the East-West interaction.

In 1986, the Department of Archaeology of Peking University and the Institute of Cultural Relics and Archaeology of Gansu Province discovered some fragments of stone mace-heads at several loci during the Hexi Corridor field explorations in Gansu Province (GPICR and SAMPU 2011). In the summer of 1987, during the excavation at Gangu'ya Cemetery of Jiuquan, Gansu, one boulder mace-head was uncovered in burial 44 (Fig. 2) (SAMPU and GPICR 2012). These important discoveries attracted my attention and drew me to further investigate this question.
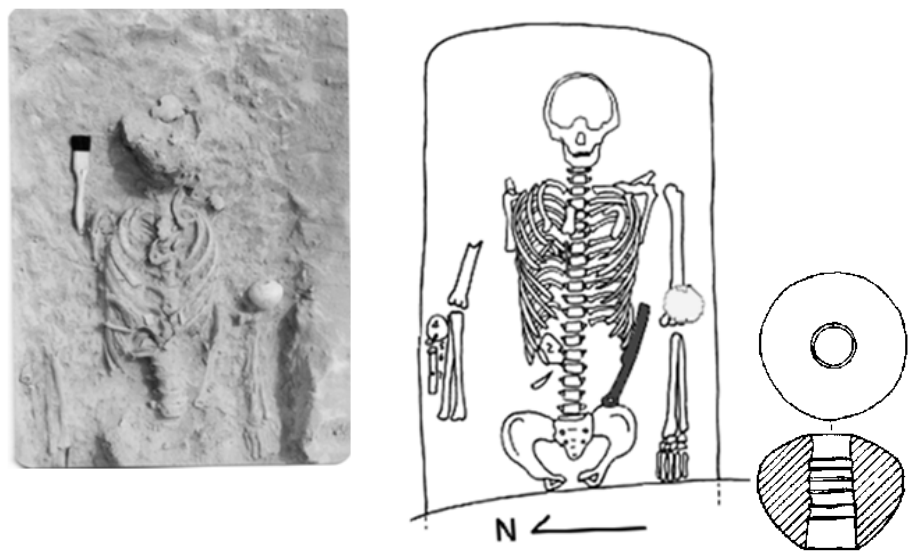

Fig. 2. the burial 44 of Gangu'ya Cenetery of Jiuquan County, Gansu

In fact, similar mace-heads had been discovered in earlier years before our project, and were unearthed in later archaeological works. These examples are as follow: Huoshaogou Cemetery of Yumen, Gansu (Museum of Gansu Province 1994: 41); Ningjiazhuang site (Wang 1995) of Xihe County; Dadiwan site (Archaeological Team of Gansu Musuem 1983) of Qin'an County (Fig. 3.1); Qijiaping site of Guanghe County (Fig. 3.2); Maojiaping site (ATGM and DAPU 1987) of Gangu County, Gansu Province; burial no. 13 at Zhu'yuan'gou (Baoji Museum 1988: 71), Baoji city (Fig. 3.3); Bodong tomb (Luo 1993: 118-20) of Fufeng County (Fig. 3.4), Shaanxi. The material of these maceheads include ceramic, jade, stone and bronze. These items date the Yangshao Culture, which is equivalent to 5000 BP, to the subsequent Majiayao Cultury (3000-2000 BCE), Qijia Culture (2300-1600 BCE), Siba Culture (1950-1550 BCE), Shajing Culture (1000-500 BCE) and up until the Zhou dynastic period (the first millennium BCE). 


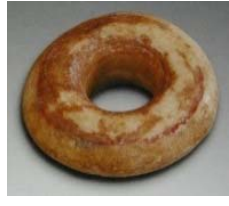

1

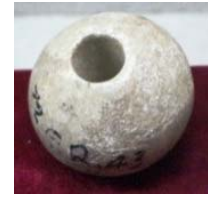

2
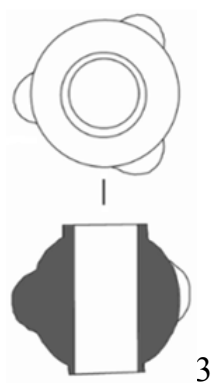

3

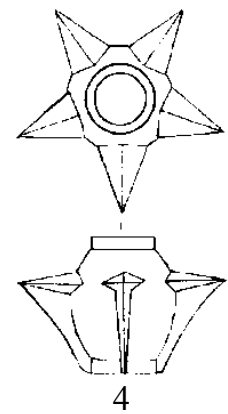

Fig. 3

To the west of the Gansu Province in the Xinjiang Uygur Autonomous Region, there mace-heads are more commonly found. These sites include the Erdaogou site of Hami city (Fig. 4.1), Xiaohe Cemetery (Qi and Wang 2008: 27) of Ruoqiang County (Fig. 4.2), Hongqijiqichang site (Museum of Qitai County 1982) of Qitai County (Fig. 4.3), Sa'nsayi Cemetery (Ruan et al. 2010) of Urumchi (Fig. 4.5), Ni'ya site (XWSG and SM et al. 1998: 80) of Minfeng County (Fig. 4.4) etc. The material of these mace-heads also include jade, stone and bronze, all dating to the Neolithic and Bronze Age (or possibly later).

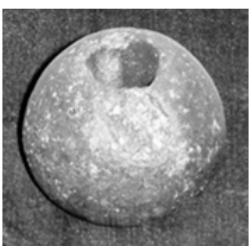

1

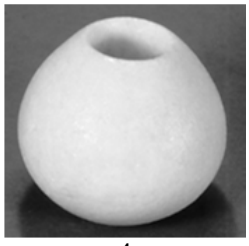

4

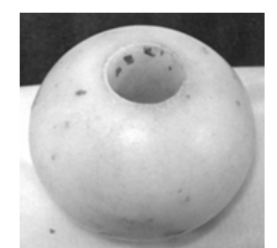

2

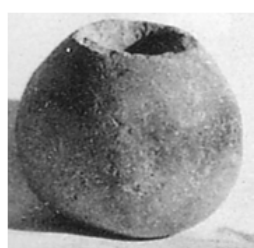

3

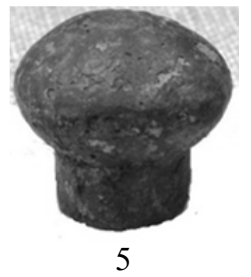

Fig. 4

One point must be clarified here. In scholarship, some Chinese scholars have mistaken mace-heads as daily-use tools or common weapons. But my analysis below demonstrates the function of mace-heads is not this case. 
But where did these Chinese mace head examples come from? This is indeed a question of great importance and is worthwhile further investigation. The earliest mace head examples come from the Near East during the PPNA period. An early example is the stone mace head from the site of Hallan Cemi in Antolia, Turkey, dated to 9500-8500 BCE (Fig. 5.1-2). Another contemporary example is the stone mace-head from Körtik Tepe (Fig. 5.3). At Can Hasan a copper mace-head was unearthed dating to 5000 BCE - the earliest known metal mace-head discovered to date (Fig. 5.4) (Wertime 1973).

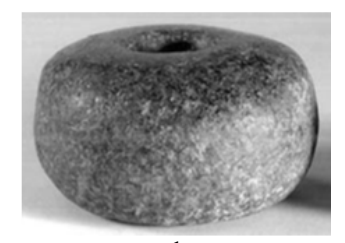

1

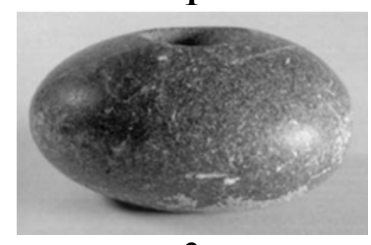

3

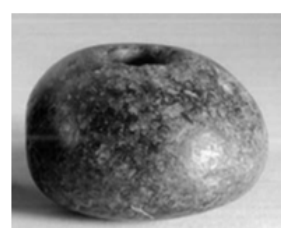

2

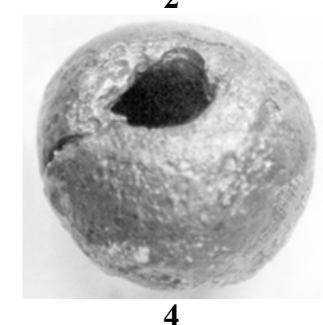

Fig. 5

In Mesopotamia, the earliest mace-heads can also be traced back to around this time, or equivalent to the PPN period (8300-6000 BCE) (Kozłowski 2002: 117). They are mostly ball-shaped or pear-shaped. Besides boulder and bronze materials, mace-heads were also made by chalcedony or glass, suggesting that they were in fact items of prestige goods. Some of the boulder mace-heads were carved with cuneiforms or figures and animal embossments on their surface (Fig. 5, 1-3). At the end of the 19th century, an exquisite mace head belonging to King Mesalim, one of the most precious relics of the Ur dynasty period, was excavated from the ruins of Lagaš in southeast Baghdad (Hrouda 1991). In the exhibition of the Near East section at the Museum of Pennsylvania University, there is one white mace-head from the third Kingdom of Ur (2500 BC) with cuneiforms on the surface saying 'Consecrated to Goddess Shara' (Fig. 6.4). Stylistically, this mace-head is quite similar to the one found in tomb no.44 at the Ganguya cemetery in Gansu, although the latter does not include any inscriptions. 


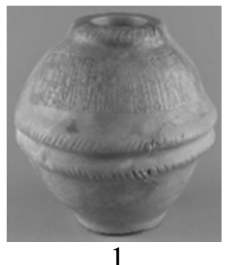

1

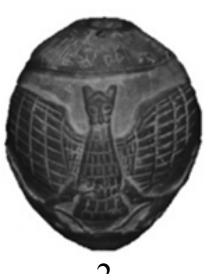

2

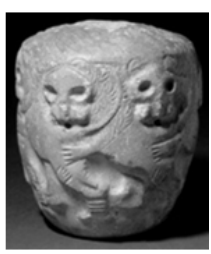

3

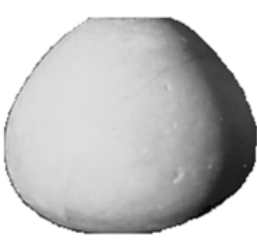

4

Fig. 6

The earliest mace-heads from the Levant can also be traced back to around the PPN period. In 1961, remains of a remarkable hoard were unexpectedly found in the cave of Nahal Mishmar to the west of the Dead Sea. The collection contained more than 400 metal objects, of which a fairly large amount was scepters and mace-heads. Some of these artifacts had handles, and some had crosses or figures of animal decorations made with the lost-wax casting technique. The casting of such objects required a high level of skill since the bronze was rich in arsenic and antimonyelements, according to scientific analysis. These artifacts date to the fourth millennium BCE (Fig. 7) (National Geographic Society 1999).

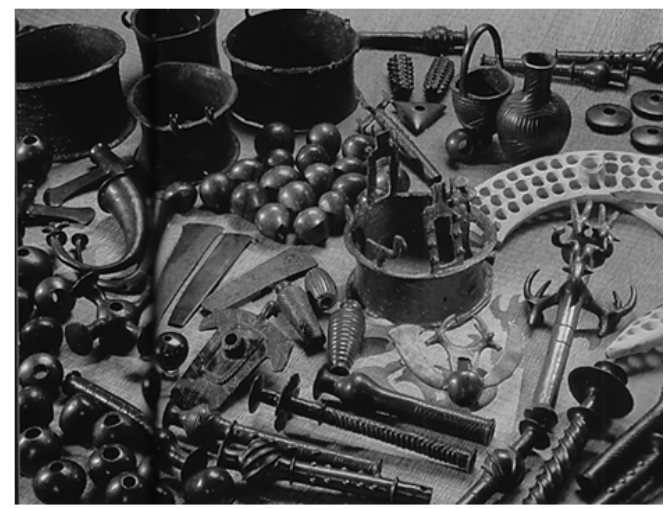

Fig. 7. Mace-heads from Nahal Mishmar cave

As I allured to before, the mace-head is more than a weapon. It is a unique object that has a ritual role symbolizing one's authority and prestige. In Dorak, near the Marmara Coast, two magnificent tombs have been unearthed, and one was the final resting place of a local king. A mace mounted with a wooden handle was placed in his arms. The other tomb was a joint burial for a king and his queen. In this case too, a mace with a wooden handle was placed above each individual's arm. The two tombs clearly reflected elite status as they were stacked with luxurious burial articles, and date to 2553-2539 BCE (Fig. 8) (Piggott 1961). 


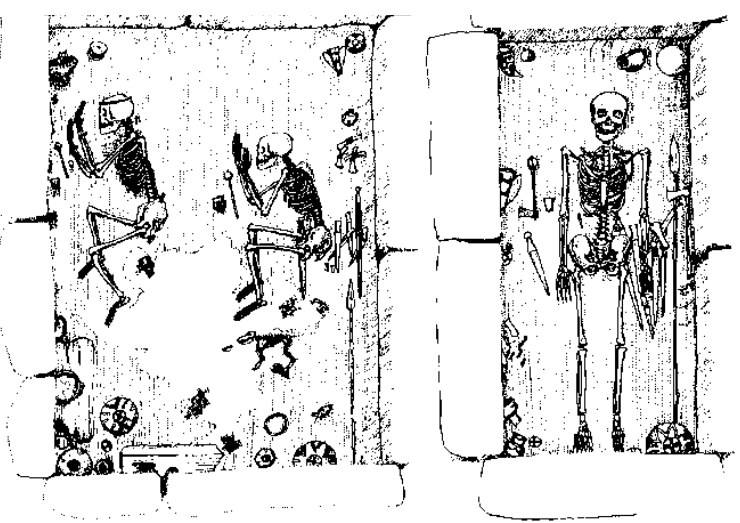

Fig. 8

At around $1000 \mathrm{BCE}$, the making and using of mace-heads had gradually become prevalent in the Near East, yet the bronze mace-heads still remained highly significant in the demonstration and legitimation of elite status and authority. The scene of kings and elites using mace was a common motif in Near Eastern and Mesopotamian art. Kings, aristocracy, and warriors are frequently found holding maces Akkadian, Assyrian, Babylonian, and Hittite stone artwork. The undefeatable image of these iconographies is so clear and prominent that the political propaganda message behind these artworks can be easily identified even through our modern eyes (Roaf 1999: 153) (Fig. 9).
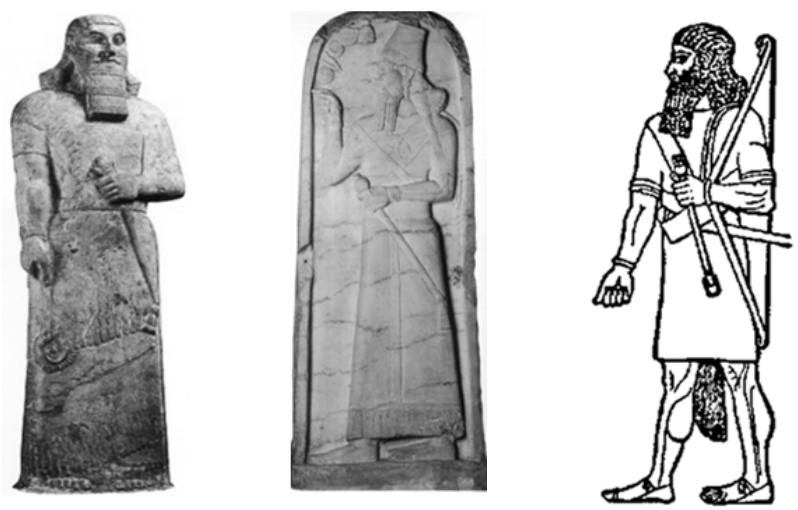

Fig. 9

One of the areas where the largest number of maces has been discovered is the Ancient Egyptian Kingdom in Northern Africa. In the Nubian kingdom in the Upper Nile, mace-heads have been found dating to the late 
Neolithic period (4000 BCE), and are probably the first North Africa macehead example. As early as the Pre-dynastic period (before 3050 BCE), maces were already quite widespread. There were three different types of mace-heads in ancient Egypt: 1) shuttle-shaped with two points (Fig. 10.1);2) circle slice-shaped, wider on the top but dwindled at the bottom (Fig. 10.2); 3) and pear-shaped or ball-shaped (same as which were found in China) (Fig. 10.3). All mace-head types could be mounted through a hole in their center. Several mace-heads were carved with enlaced decorative designs of relief and papilla on their surface, and all were made with fine and scarce materials. It is important to point out that these three types of mace-heads were all found in the Levant before they are known in Egypt.

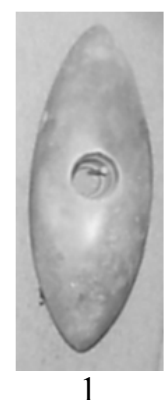

1

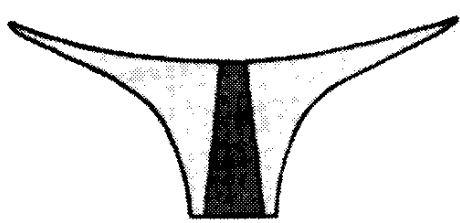

2

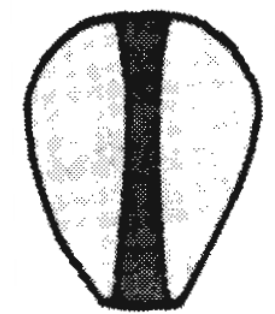

3

Fig. 10

Mace-heads are prominently displayed in Egyptian artwork and their use is clearly depicted in paintings, sculptures, and other artworks. The earliest case is found on the wall-painted tomb in Hierakonpolis during the Pre-dynastic period, in which a warrior (identified as the King) waving a mace at a trussed captive was depicted (Kemp 1995: 61). This theme - depicting conquerors striking bound captives with a mace - then became a common motif in Egyptian artwork and can be found on painted murals, stone carvings, and ceramic labels. Perhaps the most famous example of these depictions is the one found on the Narmer Palette, which was also unearthed at Hierakonpolis. It is 63 centimeters high with double-faced anaglyphs. The palette commemorates King Narmer's victory against northern foes and marks, for many, the beginning of First Egyptian Kingdom. One side of the palette shows King Narmer, wearing the white crown of Upper Egypt and holding a mace about to strike a captive kneeling on the ground. The other is separated into three parts: two huge monstrous animals intertwined with each other in the middle part and the conquering images both in the upper and lower columns. The upper column shows King Narmer, wearing the red crown of Lower Egypt and holding a mace inspecting two lines of beheaded and bound captives as he is accompanied by his subordinates (Fig. 11). 

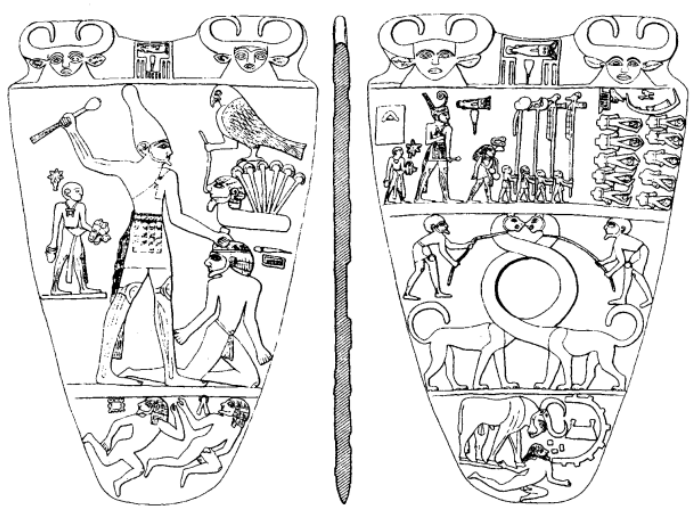

Fig. 11

In the famous tomb of Pharaoh Tutankhamun, two luxuriant goldplated statues measuring 190 centimeters in length with a golden mace in their hands were unearthed. Some scholars have suggested that these statues depict the King Tutankhamun himself (James 2000).

Mace-heads are less known in Europe since much fewer examples have been unearthed. Between the Dnepr River and Don River, at the North bank of the Azov Sea, a number of mace-heads have been found in burial contexts belonging to the Skelya Culture (4550-3000 BCE) (Levine et al. 1999). These are probably the earliest mace-head examples in Europe identified so far. A white stone mace-head is exhibited in the European section at the Anthropology Museum of Cambridge University of England. This mace-head dates to the second millennium BC, and is from the Tisza Valley which stretches from Hungary to Yugoslavia.

A number of bronze mace-heads from the Tli burial ground located at the south piedmont of Caucasia Mountaind have been found as well. The mace-heads were round or elliptical: some were cast, and there are four to five strumae-like or spiral shell-shaped protruding nubs on the surface, an element not only for decoration but also for enhancing attacking ability; some carved with horses, fish, snakes, birds and tiger-eating-people designs (Chernykh 1992: 480-1) (Fig. 12). The design of these artifacts demonstrates an extraordinary artistic style. One mace-head of this type with five strumae-shaped nubs is morphologically close to the one with four goat heads unearthed at the Huoshaogou Cemetery of Yumen, Gansu, and the one from burial no.13 of Zhuyuangou, Baoji city, China. Similar mace-heads were also discovered at Borodino hoard of Moldavia (Chernykh 1992: 480-1) and the tomb of King Dorak, near the Marmara Coast, dating from about the same time. 

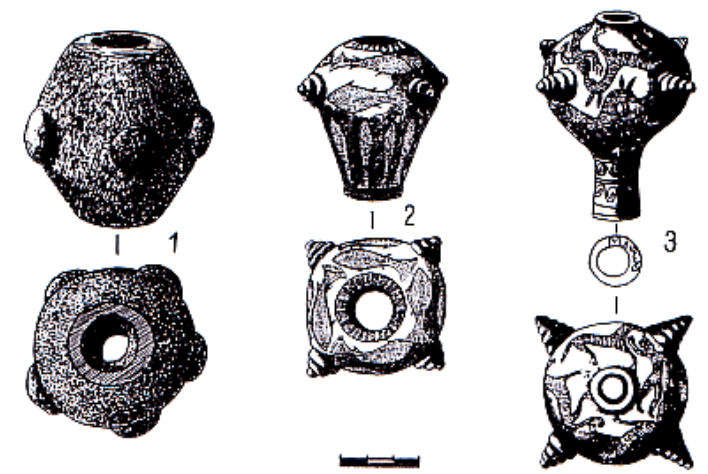

Fig. 12

Central Asian mace-head examples are mostly dated to the Bronze Age period. At the Bactrian-Margiana Culture (2000-1800 BCE) of Uzbekistan, boulder or bronze mace-heads were unearthed (Sarianidi 1981). In the Sintashta Valley of South Ural, archaeologists from the former Soviet Union have excavated one site belonging to the Sintashta-Petrovka Culture. At this site a passel of boulder mace-head was unearthed, which was mainly round and elliptical and quite similar to the counterpart in Northwestern China. Dating to roughly 2000BCE they are contemporary to the Chinese early examples as well (Fig. 13) (Ghening, Zdanovich, and Ghening 1992).

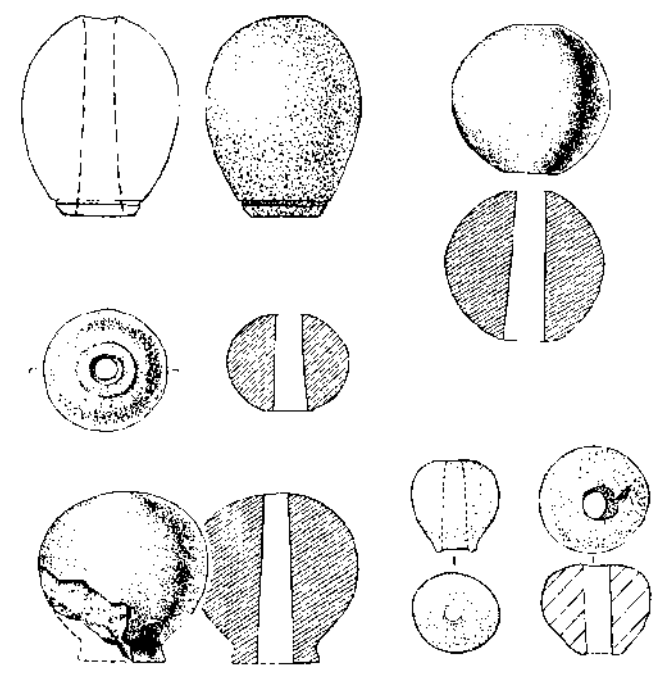

Fig. 13 


\section{CONCLUSION}

The archaeological evidence available so far has revealed that the earliest mace-heads first appeared in the Near East about 10000 BP. along with the early development and spread of agriculture. After that mace-heads began to spread throughout the ancient world: southward to Ancient Egypt Kingdom in North Africa, and northwest to Europe and then to the Eurasian steppe of central Asia and Siberia. Eventually, this movement gradually arrived at the Northwestern region of China (Fig. 14).

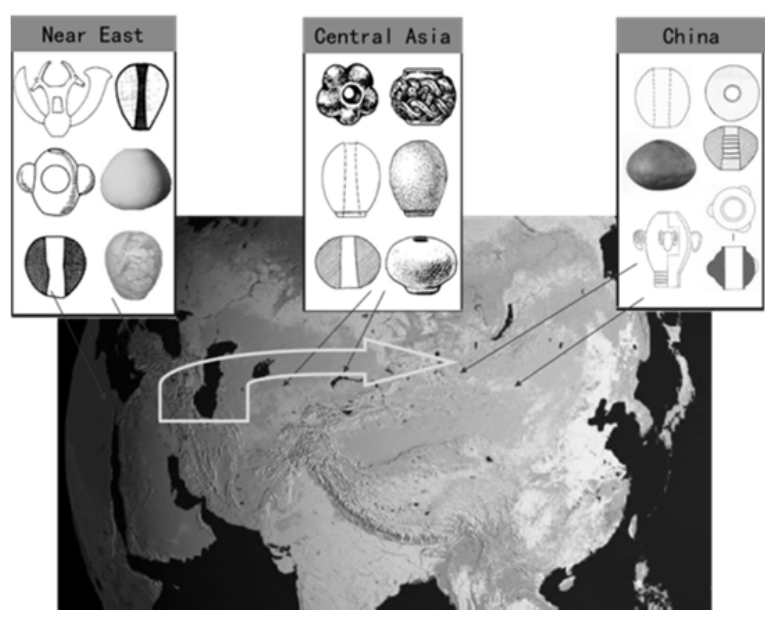

Fig. 14

Mace-heads were a special artifact for the display of status and symbolized authority limited to noble and elite warrior classes. The discoveries in Dorak showed that only the kings were qualified to use maces. In Ancient Egypt and the Near East, a large number of carvings representing mace-head holders have confirmed the unique functions of maces. One can argue that this tradition persisted and last even today and was illustrated by British beefeaters as well as Ukrainian and Argentinian president guards.

This unique social function of mace heads was maintained when they were introduced to China. For example, of the 167 excavated tombs at Xiaohei in Xinjiang, only one mace head was uncovered in the largest tomb in the cemetery. Similarly, among the 107 tombs excavated in Gangu'ya Cemetery of Jiuquan, Gansu, there was only one contained mace-head. Also the burial articles in this tomb were more prestige than those in the whole cemetery. Similarly, among the 306 tombs excavated in Huoshaogou Cemetery, only 10 mace-heads were unearthed.

In China, mace-heads were found only in Xinjiang, Gansu, Qinghai and Western Shaanxi in Northwestern China (Li 2012: 20-5). In fact, the 
morphology of these objects is quite similar to those found outside China. Thus we can assume that maces, as they bear special and symbolic functions, are not the original or indigenous cultural trait of Chinese civilization. Instead, they are more likely to be exotic goods coming from outside. As I argued before, the reasons can be summarized as follow: first, mace-heads in the Near East significantly predate all counterparts in China. Second, the amounts of mace-heads found in China are relatively limited. Third, mace-head discoveries in China are concentrated only in the northwestern area, a pattern explicitly indicating the western origin of this type of artifacts.

Right upon its arrival, mace-heads seemed to generate a deep impact in northwest China along the Great Wall. From an archaeological perspective, however, the Central Plains, or known as the core-zone of ancient Chinese civilization, did not accept this exotic cultural trait at all, which was clearly demonstrated by the sporadic discoveries in Shaanxi and western Henan. Instead, the core-zone of ancient Chinese civilization had developed a system using fu and yue axes as symbols of authority and power from its very beginning. More importantly, this case study shows that for a given ethnic group or community, the acceptance and adoption of certain exotic cultural practices will be highly selective and within certain limitation. The understanding of this issue can not only shed insight on history but also disclose an essential aspect in social reality.

The introduction of mace-heads in China also provides important lines of information on cultural interaction and exchange between the East and West. First, it provides inarguable evidence documenting some of the earliest interactions before $5000 \mathrm{BP}$. In fact, the mace-heads is just one of the many artifacts in the package from the West that were adopted in China during this period (e.g., sheep goat metallurgy, wheat, etc.). The impacts that each element had imposed on different parts of Western China through cultural contact varied widely in term of the scale and scope. In addition, the fact that the most frequent interaction through mace-heads took place in China around the second millennium BCE - the period overlapped with the rise of the royal dynasty of ancient China - should be seen as more than merely coincidence. Perhaps there are some deep historical factors that made this interaction inevitable. Indeed, more research and scholarship on this matter is necessary.

History also proves that regional interaction played a dynamic role in stimulating the early development of different human societies, cultures, cities and states. In addition, the continued investigation of newly excavated archaeological materials will significantly benefit the development of a deeper understanding of the processes by which ancient civilizations have evolved. 


\section{ACKNOWLEDGEMENT}

I am very grateful to Professor Rowan K. Flad (Harvard University), Yitzchak Jaffe (Doctoral candidate, Harvard University) and Dr. Weng Cheong Lam (Harvard University), for their great help in translating this paper from Chinese into English.

\section{REFERENCES}

Andersson, J. G. 1923. An Early Chinese Culture. Bulletin of the Geological Survey of China, Vol. 1, No. 5. Translated by Yuan, Fuli. Peking: Jinghua Publishing House.

Andersson, J. G. 1925. Preliminary Report on Archaeological Research in Kansu. Translated by Le, Senxun. Memoirs of the Geological Survey of China 5.

Archaeological Team of Gansu Museum and Dept. of archaeology of Peking University. 1987. The Report of excavation in Maojiaping site of Gangu, Gansu (甘肃甘谷毛家坪遗址发掘报告). Acta Archaeological Sinica 3: 359-396.

Ghening, V. F., Zdanovich, G. B., Ghening V. V. 1992. Sitashta. Chelyabinsk: Yuzhno-Uralskoe knishnoe izdatelstvo. In Russian (Генинг В. Ф., Зданович Г. Б., Генинг В. В. Ситашта. Челябинск. Южно-Уральское книжное издательство).

Chernykh, E. N. 1992. Ancient Metallurgy in the USSR - The Early Metal Age. Cambridge: Cambridge University Press.

Gansu Province Institute of Cultural Relics and Archaeology, and School of Archaeology, and School of Archaeology and Museology, Peking University. 2011. The Report on the Survey of Prehistoric Archaeology in the Hexi Corridor (河西走廊史前考古调查报告). Beijing: Cultural Relics Press.

James, T. G. H. 2000. Tutankhamun. Fairfax, Virginia: Friedman.

Hrouda, B. 1991. Der Alte Orient, Geshichte und kultur des alten Vorderasien. München: C. Bertelsmann Verlag.

Kemp, B. J. 1995. Ancient Egypt: Anatomy of a Civilization. London: Routledge.

Kozłowski, S. K. 2002. Nemrik: An aceramik Village in Northern Iraq. Warsaw: Institute of Archaeology, Warsaw University.

Levine, M., Rassamakin, Y., Kislenko, A., and Tatarintseva, N. (eds.) 1999. Late Prehistoric Exploitation of the Eurasian Steppe. Cambridge: McDonald Institute Monographs for Archaeological Research, University of Cambridge.

Li, Shuicheng. 2002. Interaction between Northwest China and Central Asia during the Second Millennium B.C.: An Archaeological Perspective. In Late Prehistoric Exploitation of the Eurasian Steppe (chap. 2, 1-12). University of Cambridge.

Li, Shuicheng 2012. A Disscussion on the Maceheads from the Chifeng and Surrounding Regions (赤峰及周边地区考古所见权杖头及潜在意义). In Festschrift for Prof. Su Bai's 90th Birthday (庆祝宿白先生九十华廹). Edited by Society for Chinese Archaeology and Shenyang Institute of Archaeology. Beijing: Science Press. 
Luo, Xizhang, (ed.) 1993. The Collections of Relics in Fufeng County (扶风县文 物志). Xi'an: Shaanxi People's Education Press.

Museum of Baoji City, (ed.) 1988. The Yuguo Cemetery in Baoji (宝鸡魥国墓地). Beijing: Cultural Relics Press.

Museum of Gansu Province. (ed.) 1994. The Silk Road: Relics Quintessence of Gansu (丝绸之路 - 甘肃文物精华). Lanzhou: Museum of Gansu Province.

Museum of Qitai County. 1982. The New Discovery in Qitai county, Xinjiang. In Collected Papers in Archaeology (pp. 22-24). Beijing: China Social Sciences Press.

National Geographic Society. 1999. Crafts for Ritual and Trade. National Geographic 195 (4).

Piggott, S. 1961. The Dawn of Civilization. London: McGraw-Hill.

Qi, Xiaoshan, and Wang Bo. (eds.) 2008. The Archaeology of the Silk Road and Xinjiang (丝绸之路·新疆古代文化). Urumuqi: Xinjiang People's Press.

Roaf, M. 1999. Culture Atlas of Mesopotamia and the Ancient Near East. New York: Facts on File.

Ruan, Qiurong et al. 2010. The Excavation in the San'sayi's Cemetery of Urumuqi, Xinjiang (新疆乌鲁木齐萨恩萨依墓地发掘). In Major Archaeological Discoveries in China in 2009 (2009中国重要考古发现). Edited by State Administration of Cultural Heritage. Beijing: Cultural Relics Press.

Sarianidi, V. I. 1981. Margiana in the Bronze Age. In Kohl, P. (ed.), The Bronze Age Civilization of Central Asia: Recent Soviet Discoveries (pp. 165-193). New York: M. E. Sharp.

School of Archaeology and Museology, Peking University, and Gansu Province Institute of Cultural Relics and Archaeology. 2012. The Excavations of the Gangu'ya Cemetery in Jiuquan City, Gansu (甘肃酒泉干骨崖墓地的发掘与 收获). Acta Archaeological Sinica 3: 351-368.

Su, Bingqi. 1997. A New Investigation into the Origin of Chinese Civilizations (中 国文明起源新探). Hong Kong: The Commercial Press.

Wang, Junyan. 1995. The Painted Mace-head unearthed in Ningjiazhuang of Xihe County, Gansu (甘肃西和县宁家庄出土的彩陶权杖头). Archaeology 2: 184-185.

Wertime, T. A. 1973. The Beginning of Metallurgy: A New Look. Science 4115: 875-887.

Xinjiang Administration of Cultural Relics, and Museum of Shanghai, et al., (eds.) 1998. Archaeological Treasures of the Silk Road in Xinjiang Uygur Autonomous Region (维吾尔自治区丝绸之路考古遗珍). Shanghai: Translation Publishing House. 
272 Social Evolution \& History / September 2018

Acronyms:

GPICR: Gansu Province Institute of Cultural Relics and Archaeology

SAMPU: School of Archaeology and Museology, Peking University

ATGM: Archaeological Team of Gansu Musuem

DAPU: Dept. of archaeology of Peking University

XWSG: Xinjiang Wenwu Shiye Guanliju

SM: Shanghai Museum 